\title{
RECEPTORES ITERATIVOS PARA CANAIS MIMO SELETIVOS EM FREQÜÊNCIA E QUASE ESTÁTICOS: UMA ANÁLISE COMPARATIVA
}

\author{
Richard Demo Souza
}

\begin{abstract}
Resumo - Neste trabalho, são introduzidos dois esquemas diferentes de recepção iterativa, para a transmissão de dados submetidos à codificação espaço-temporal em canais seletivos em freqüência com desvanecimento quase estático. Ambos os esquemas operam de forma semicega e fazem uso do algoritmo da maximização da esperança para estimar o canal desconhecido. A diferença entre os dois métodos está no fato de que deteç̧ão e decodificação de máxima-a-posteriori são realizadas sobre uma supertreliça ou sobre treliças separadas. Os dois esquemas são comparados em termos de complexidade de treliça, nível de diversidade e taxa de erro de bit. Tal comparação mostra que o método que utiliza a supertreliça demanda menor esforço computacional e apresenta convergência mais veloz. Por outro lado, o método baseado nas treliças separadas é capaz de atingir um nível de diversidade mais elevado e, consequientemente, uma taxa de erro de bit menor. Essa relação custo-benefício é investigada através de exemplos e simulações computacionais. Os resultados obtidos evidenciam que, em geral, o método baseado na supertreliça é uma solução mais interessante do que o baseado nas treliças separadas.
\end{abstract}

Palavras-chave: Equalização turbo, canais MIMO, códigos espaço-temporais, algoritmo EM, estimação de canal.

\begin{abstract}
We introduce two different iterative receivers for space-time coded data transmitted through frequency selective fading channels. Both receivers operate semi-blindly and make use of the expectation maximization algorithm for estimating the unknown channel. The approaches differ in the sense that maximum-a-posteriori data detection and decoding are either performed over a supertrellis or over separate trellises. The two approaches are compared in terms of trellis complexity, achievable diversity level, and bit error rate. The supertrellis approach shows to be less computational demanding and has a faster convergence rate. The separate approach can achieve a higher diversity level and thus a smaller bit error rate. We explore this trade-off with examples and computer simulations. These show that, in many cases, the supertrellis approach can be a better solution than the separate approach.
\end{abstract}

Keywords: Turbo equalization, MIMO channels, space-time codes, EM algorithm, channel estimation.

Richard Demo Souza está vinculado ao Programa de Pós-Graduação em Engenharia Elétrica e Informática Industrial (CPGEI), Centro Federal de Educação Tecnológica do Paraná, CEFET/PR, Curitiba, PR, Brasil. E-mail: richard@cpgei.cefetpr.br. Editor de Área responsável: Ricardo Campello. Artigo submetido em 29/Jan/2004, revisado em 30/Jun/2004, aceito em 16/Jul/2004.

\section{INTRODUÇÃO}

De forma independente, Telatar [1] e Foschini e Gans [2] demonstraram que é possível elevar consideravelmente a capacidade de sistemas de comunicação sem fio através da utilização de múltiplas antenas, tanto no transmissor quanto no receptor. Motivados por esses importantes resultados na esfera da teoria da informação, Tarokh et al [3] introduziram os chamados códigos espaço-temporais (STC's), em que a redundância é inserida de forma apropriada tanto no espaço (antenas transmissoras) quanto no tempo, de modo que ganhos de diversidade e de código possam ser obtidos simultaneamente.

Os STC's já foram analisados extensivamente para o caso de um canal com desvanecimento plano [3-7]. Porém. quando se considera taxas de transmissão muito altas, situação na qual a largura de banda do sinal a ser transmitido ultrapassa a da banda de coerência $[8,9]$, o canal começa a apresentar seletividade em frequiência e, portanto, interferência entre os símbolos (IES). Para lidar com esse problema, algumas técnicas diferentes de detecção (equalização) foram propostas e analisadas por vários pesquisadores nos últimos anos [10-13]. Em [10-12], o canal é considerado perfeitamente conhecido no receptor. Já em [13], a estimação do canal é feita de forma não iterativa e baseada no critério do erro quadrático médio mínimo.

Entretanto, a questão de se estimar o canal com múltiplas entradas e múltiplas saídas (MIMO) pode ser vista como um problema de máxima verossimilhança (ML) baseado em dados incompletos. Nesse tipo de situação, o algoritmo da maximização da esperança (EM) [14-16] tem se demonstrado uma ferramenta bastante atraente e efetiva. Aplicações do algoritmo EM no projeto de receptores iterativos para o caso de canais MIMO planos [17-21] podem ser facilmente encontradas na literatura especializada.

A solução clássica para a equalização de máxima-aposteriori (MAP) para sistemas MIMO demanda um grande esforço computacional, uma vez que o número de estados do equalizador cresce exponencialmente com o aumento do número de antenas transmissoras e do comprimento da IES. Recentemente, algumas técnicas baseadas em pré-filtragem $[12,13]$ e na inserção do codificador espaço-temporal dentro do modelo do canal [11] foram propostas como alternativas menos complexas.

Este trabalho apresenta uma construção alternativa, na qual o modelo Markoviano que representa o canal é inserido na treliça do STC, o que resulta em uma "supertreliça". Devido às fortes restrições impostas pelo STC, detecção e decodificação conjunta podem ser realizadas com complexidade computacional reduzida. A supertreliça pode ser cons- 
truída para qualquer STC, enquanto que inserir o codificador espaço-temporal dentro do modelo do canal, como proposto em [11], requer a existência de uma transformação linear que relacione os símbolos a serem transmitidos pela primeira antena àqueles que devem ser transmitidos pelas demais. Além disso, ao contrário de [11-13], o canal MIMO é considerado desconhecido e o receptor é projetado com base no algoritmo EM, que realiza a estimação de canal, detecção e decodificação de forma iterativa e semicega. Métodos semicegos $[22,23]$ utilizam tanto símbolos conhecidos (treinamento) como desconhecidos (informação) durante o processo de estimação. Dessa forma, eliminam os problemas de convergência inerentes aos métodos cegos e necessitam de um número de símbolos conhecidos menor em relação aos métodos treinados.

O desempenho do receptor iterativo semicego baseado na supertreliça, realizando detecção e decodificação conjunta, é comparado com o de um receptor iterativo semicego baseado em treliças separadas, realizando detecção e decodificação combinadas. Essa comparação mostra que uma iteração do receptor baseado na supertreliça requer menor esforço computacional do que uma iteração do receptor baseado em treliças separadas. Além disso, a convergência para o caso da supertreliça é mais rápida, o que faz com que a complexidade computacional total seja reduzida ainda mais. Entretanto, diferentemente do caso da supertreliça, o uso de treliças separadas permite que um entrelaçador de canal seja utilizado antes da transmissão dos dados. Esse procedimento possibilita a obtenção de um nível de diversidade mais alto [24] e, conseqüentemente, de uma menor taxa de erro de bit (BER). Portanto, o receptor baseado na supertreliça demanda menor custo computacional, mas pode apresentar pior desempenho do que o baseado em treliças separadas. Logo, há uma relação custo-benefício a ser explorada entre as duas técnicas.

Este trabalho está dividido em sete seções. A Seção 2 apresenta o modelo do sistema a ser considerado. A Seção 3 aborda a estimação do canal e da variância do ruído, enquanto que a Seção 4 apresenta os dois esquemas para detecção e decodificação: o que utiliza a supertreliça e o que utiliza treliças separadas. A Seção 5 discute a respeito da combinação de forma semicega dos estágios de estimação do canal e da variância do ruído, e de detecção e decodificação. A Seção 6 compara as duas técnicas apresentadas (supertreliça e treliças separadas) em termos de complexidade computacional, com base na complexidade de treliça [25], no nível de diversidade [24] e na BER. Por fim, a Seção 7 apresenta os comentários finais.

\section{MODELO DO SISTEMA}

Considere um sistema de comunicações sem fio envolvendo $N$ antenas transmissoras e $M$ antenas receptoras, como o mostrado na Figura 1, em um ambiente com IES e desvanecimento Rayleigh. O sinal recebido pela $j$-ésima antena no instante de tempo $k, x^{j}(k)$, é dado por:

$$
x^{j}(k)=\sum_{i=1}^{N} \sum_{d=0}^{D-1} \sqrt{\Phi_{s}} s^{i}(k-d) h_{i, j}(d)+\eta^{j}(k),
$$

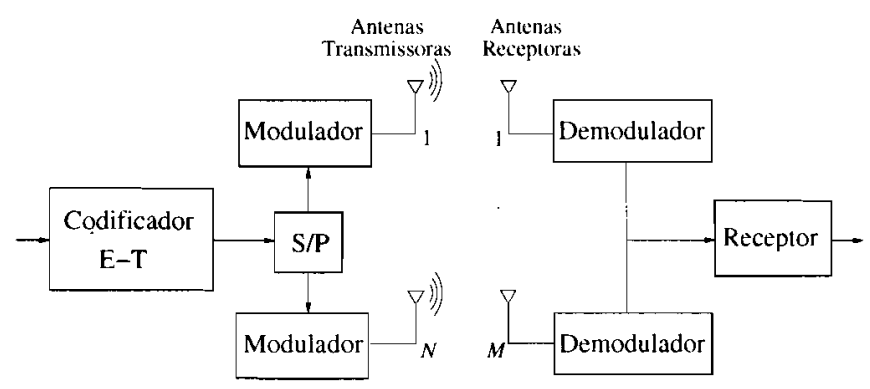

Figura 1. Diagrama de blocos de um sistema de comunicações sem fio com codificação espaço-temporal, $N$ antenas transmissoras e $M$ antenas receptoras.

onde $s^{i}(k)$ é um símbolo de uma constelação $m$-PSK que representa o dado na saída de um codificador espaço-temporal [3] e que é transmitido pela antena $i$ no instante $k$; a entrada do codificador espaço-temporal no instante $k$ é uma palavra binária de comprimento $\log _{2} m$, denotada por $u(k) ; \Phi_{s}$ é a energia média do sinal a ser transmitido através do canal: $\eta^{j}(k)$ é um ruído Gaussiano complexo, branco, de média nula e variância $N_{0} / 2$ por dimensão; $(D-1)$ é o comprimento da IES e

$$
\mathbf{h}_{i, j}=\left[h_{i, j}(0) h_{i, j}(1) \ldots h_{i, j}(D-1)\right]^{T}
$$

é a representação FIR, de energia unitária, do canal seletivo em freqüência entre as antenas $i$ e $j$, onde $h_{i, j}(d)$ são variáveis aleatórias Gaussianas complexas, independentes e identicamente distribuídas, com média nula, e variância $\sigma_{d}^{2}$, onde $\sum_{d=0}^{D-1} \sigma_{d}^{2}=1$, e o sobrescrito ${ }^{T}$ denota transposição. Os desvanecimentos $h_{i, j}(d)$ são constantes durante um bloco de informação e mudam independentemente de um bloco para outro. É interessante expandir essas definições para um modelo matricial, no qual os sinais $x^{j}(k)$ recebidos em cada uma das $M$ antenas no instante $k$ possam ser expressos por:

$$
\mathbf{x}_{k}=\mathbf{S}_{k} \mathbf{h}+\eta_{k}
$$

onde $\mathbf{x}_{k}$ é um vetor $M \times 1 ; \mathbf{S}_{k}=\mathbf{I}_{M} \otimes \mathbf{s}_{k}^{T}$ é uma matriz $M \times N M D$;

$\mathbf{s}_{k}=\left[s^{1}(k) \cdots s^{1}(k-D-1) s^{2}(k) \cdots s^{N}(k-D-1)\right]^{T}$

é o vetor de dados $N D \times 1 ; \mathbf{I}_{M}$ é a matriz identidade $M \times M$; $\otimes$ é o produto direto;

$$
\mathbf{h}=\left[\begin{array}{llll}
\mathbf{h}_{1,1}^{T} & \mathbf{h}_{2,1}^{T} & \cdots & \mathbf{h}_{N, M}^{T}
\end{array}\right]^{T}
$$

é o vetor de canal $N M D \times 1 \mathrm{e}$

$$
\eta_{k}=\left[\eta^{1}(k) \eta^{2}(k) \cdots \eta^{M}(k)\right]^{T}
$$

é o vetor de ruído $M \times 1$.

Em termos de um bloco contendo $L$ símbolos, pode-se reescrever as equações anteriores como:

$$
\mathbf{x}=\mathbf{S h}+\eta,
$$

onde

$$
\mathbf{x}=\left[\begin{array}{llll}
\mathbf{x}_{1}^{T} & \mathbf{x}_{2}^{T} & \cdots & \mathbf{x}_{L}^{T}
\end{array}\right]^{T}
$$


é um vetor $L M \times 1$;

$$
\mathbf{S}=\left[\begin{array}{llll}
\mathbf{S}_{1}^{T} & \mathbf{S}_{2}^{T} & \cdots & \mathbf{S}_{L}^{T}
\end{array}\right]^{T}
$$

é uma matriz $L M I \times N M D \mathrm{e}$

$$
\eta=\left[\eta_{1}^{T} \eta_{2}^{T} \cdots \eta_{L}^{T}\right]^{T}
$$

é o vetor de ruído $L M \times 1$.

\section{ESTIMAÇÃO DO CANAL E DA VARIÂNCIA DO RUÍDO}

\subsection{ESTIMAÇÃO DO CANAL}

Suponha que os coeficientes $h$ do canal sejam desconhecidos. A solução de MAP para a estimação desses coeficientes é dada por:

$$
\hat{\mathbf{h}}=\arg \max _{h} p(\mathbf{h} \mid \mathbf{x}) .
$$

Tal maximização pode ser simplificada se for considerado o algoritmo EM [14], onde $\mathrm{x}$ são os dados incompletos; $\mathbf{S}$ são os dados complementares e $\mathbf{y}=\{\mathbf{x}, \mathbf{S}\}$ são os dados completos. Assim, passa-se a utilizar a seguinte maximização de probabilidade-a-posteriori (APP):

$$
\hat{\mathbf{h}}=\arg \max _{h} p(\mathbf{h} \mid \mathbf{y}) \text {. }
$$

Através da regra de Bayes, pode-se escrever $p(\mathbf{h} \mid \mathbf{y})$ como:

$$
p(\mathbf{h} \mid \mathbf{y})=\frac{p(\mathbf{y} \mid \mathbf{h}) p(\mathbf{h})}{p(\mathbf{y})}
$$

Conseqüentemente, a sua função de verossimilhança na forma logarítmica é dada por:

$$
\mathcal{L}=\log p(\mathbf{y} \mid \mathbf{h})+\log p(\mathbf{h})-\log p(\mathbf{y})
$$

que pode ser reescrita como:

$$
\mathcal{L}=\log p(\mathbf{S} \mid \mathbf{h})+\log p(\mathbf{x} \mid \mathbf{S}, \mathbf{h})+\log p(\mathbf{h}),
$$

onde considera-se apenas os termos que dependem de $\mathbf{h}$. A substituição de $p(\mathbf{h} \mid \mathbf{y})$ por (8) em (5) geralmente simplifica a operação de maximização, sem perda de otimalidade.

Uma vez que $\mathbf{S}$ é desconhecida, considera-se primeiramente a esperança de (8) em relação a $\mathbf{S}$, e então a sua maximização para obter a estimativa $\hat{\mathbf{h}}$. Seguindo a notação de [14], a esperança é dada por:

$$
\begin{aligned}
Q\left(\mathbf{h} \mid \hat{\mathbf{h}}^{l}\right)= & \mathrm{E}_{\mathrm{S}}\left[\log p(\mathbf{S} \mid \mathbf{h}) \mid \mathbf{x}, \hat{\mathbf{h}}^{l}\right]+ \\
& \mathrm{E}_{\mathrm{S}}\left[\log p(\mathbf{x} \mid \mathbf{S}, \mathbf{h}) \mid \mathbf{x}, \hat{\mathbf{h}}^{l}\right]+\log p(\mathbf{h}),
\end{aligned}
$$

onde $\hat{\mathbf{h}}^{l}$ é a estimativa do canal disponível na iteração $l$. Como $\mathbf{S}$ é independente de $\mathbf{h}$ :

$$
Q\left(\mathbf{h} \mid \hat{\mathbf{h}}^{l}\right)=\mathrm{E}_{\mathrm{S}}\left[\log p(\mathbf{x} \mid \mathbf{S}, \mathbf{h}) \mid \mathbf{x}, \hat{\mathbf{h}}^{l}\right]+\log p(\mathbf{h}) .
$$

A função densidade de probabilidade dos dados recebidos $\mathrm{x}$ é

$$
\begin{aligned}
p(\mathbf{x} \mid \mathbf{S}, \mathbf{h})= & \pi^{-\Lambda L L} N_{0}^{-1} \\
& \cdot \exp \left[-(\mathbf{x}-\mathbf{S h})^{H} N_{0}^{-1}(\mathbf{x}-\mathbf{S h})\right],
\end{aligned}
$$

onde o sobrescrito ${ }^{H}$ significa transposta Hermitiana. A função densidade de probabilidade conjunta do canal MIMO é

$$
p(\mathbf{h})=\pi^{-N M D}|\mathbf{K}|^{-1} \exp \left[\mathbf{h}^{H} \mathbf{K}^{-1} \mathbf{h}\right],
$$

onde K é a matriz de covariância $N M D \times N M D$ do canal:

$$
\mathbf{K}=\mathrm{E}_{\mathbf{h}}\left[\mathbf{h} \mathbf{h}^{H}\right] \text {. }
$$

Substituindo (11) e (12) em (10) e ignorando algumas constantes, obtém-se:

$$
\begin{aligned}
Q\left(\mathbf{h} \mid \hat{\mathbf{h}}^{l}\right)=- & \mathrm{E}_{\mathrm{S}}\left[(\mathbf{x}-\mathbf{S h})^{H} N_{0}^{-1}(\mathbf{x}-\mathbf{S h}) \mid \mathbf{x}, \hat{\mathbf{h}}^{l}\right] \\
- & \mathbf{h}^{H} \mathbf{K}^{-1} \mathbf{h} .
\end{aligned}
$$

Seja a nova estimativa de canal definida como:

$$
\hat{\mathbf{h}}^{l+1}=\arg \max _{h} Q\left(\mathbf{h} \mid \hat{\mathbf{h}}^{l}\right),
$$

a qual pode ser encontrada derivando (14) em relação $\mathbf{a} \mathbf{h}^{H} \mathrm{e}$ igualando a zero, o que resulta em:

$$
\begin{gathered}
\hat{\mathbf{h}}^{l+1}=\left(N_{0}^{-1} \mathrm{E}_{\mathrm{S}}\left[\mathbf{S}^{H} \mathbf{S}\right]+\mathbf{K}^{-1}\right)^{-1} \\
\cdot N_{0}^{-1} \cdot \mathrm{E}_{\mathrm{S}}\left[\mathbf{S}^{H}\right] \cdot \mathbf{x} .
\end{gathered}
$$

Supondo disponível uma estimativa da variância do ruído, é necessário obter uma primeira estimativa de $E_{\mathrm{S}}\left[\mathbf{S}^{H} \mathbf{S}\right]$ e $\mathrm{E}_{\mathrm{S}}\left[\mathbf{S}^{H}\right]$ para garantir que o algoritmo $\mathrm{EM}$ possa fornecer uma estimativa do canal. Porém, uma estimativa confiável desses valores esperados não estará disponível enquanto não se tiver uma estimativa para os coeficientes do canal. Para solucionar esse problema, considera-se que os primeiros $T_{r}$ símbolos do bloco de comprimento $L$ são conhecidos no receptor. Esses símbolos permitirão que se obtenha uma primeira estimativa do canal, a qual vai ser refinada com o passar das iterações, já que os $L-T_{r}$ símbolos desconhecidos passarão a ter suas APP's estimadas. Assim, a partir da segunda iteração, uma nova estimativa do canal é obtida pela exploração conjunta tanto dos símbolos conhecidos como de uma estimativa dos símbolos desconhecidos (baseada nas APP's), caracterizando, a partir daí, a operação semicega do receptor.

\subsection{ESTIMAÇÃO DA VARIÂNCIA DO RUÍDO}

Supondo que no final da iteração $l$ uma nova estimativa do canal, $\hat{\mathbf{h}}^{l+1}$, e um conjunto de APP's dos símbolos transmitidos em cada antena, $P\left(s^{n}(k)=s^{i} \mid \mathbf{x}, \hat{\mathbf{h}}^{l+1}\right), i \in$ $\{0,1, \cdots, m-1\}$, estejam disponíveis, pode-se estimar a variância do ruído como:

$$
\hat{N}_{0}^{l+1}=\frac{1}{L M}\left|\left(\mathbf{x}-\mathrm{E}_{\mathrm{S}}\left[\mathbf{S} \mid \mathbf{x}, \hat{\mathbf{h}}^{l+1}, \hat{N}_{0}^{l}\right] \hat{\mathbf{h}}^{l+1}\right)\right|^{2},
$$

onde $\hat{N}_{0}^{l}$ é a estimativa anterior. Para prover uma estimativa inicial a ser usada na primeira iteração, considera-se $\hat{N}_{0}^{1}$ como o valor quadrático médio do sinal recebido dividido por 2, o que, como em [21], sempre superestima a variância. 


\section{DETECÇÃO E DECODIFICAÇÃO}

A estimação do canal e da variância do ruído requerem o conhecimento tanto de $\mathrm{E}_{\mathrm{S}}\left[\mathbf{S}^{H} \mathbf{S}\right]$ como de $\mathrm{E}_{\mathrm{S}}\left[\mathbf{S}^{H}\right]$. Para se obter as probabilidades necessárias para o cálculo dessas esperanças, utiliza-se dois esquemas diferentes para deteç̧ão e decodificação com saída suave, ambos baseados no algoritmo BCJR [26] modificado para modulação espaçotemporal descrito em [27].

\subsection{SUPERTRELIÇA}

Nesse caso, considera-se que o modelo Markoviano que representa o canal com IES (com $m^{D-1}$ estados) é combinado com a treliça do STC. Cada um dos estados da treliça do código é dividido em $m^{D-1}$ estados. Em seguida, considerase a decodificação de MAP sobre a supertreliça, que agora representa o canal com IES e o código. É interessante notar que a supertreliça pode ser vista como uma construção mais geral do que a introduzida em [11], em que um modelo linear para o STC é combinado com o canal com IES. A supertreliça, ao contrário do método proposto em [11], permite que se considere qualquer STC. Essa característica é muito importante, já que, em termos de ganho de codificação, os melhores STC's não são necessariamente aqueles que podem ser representados por um modelo linear, uma vez que a classe dos códigos com diversidade completa é enorme [5].

Assim, a solução de MAP a ser dada pelo detector/decodificador conjunto para a seqüência de entrada $u(k)$, dadas as observações $\mathbf{x}$, é

$$
u(k)=\arg \max _{i} P\left(u(k)=u^{i} \mid \mathbf{x}, \hat{\mathbf{h}}\right),
$$

onde $P\left(u(k)=u^{i} \mid \mathbf{x}, \hat{\mathbf{h}}\right)$ é a APP da entrada $u(k)=u^{i}$, $i \in\{0,1, \cdots, m-1\}$ e $\hat{h}$ é a estimativa atual do canal. Podese expressar essas APP's como:

$$
\begin{aligned}
& P\left(u(k)=u^{i} \mid \mathbf{x}, \hat{\mathbf{h}}\right)= \\
& \quad \sum_{\sigma_{k}} \sum_{\sigma_{k+1}} P\left(u(k)=u^{i}, \sigma_{k}, \sigma_{k+1} \mid \mathbf{x}, \hat{\mathbf{h}}\right),
\end{aligned}
$$

onde $P\left(u(k)=u^{i}, \sigma_{k}, \sigma_{k+1} \mid \mathbf{x}, \hat{\mathbf{h}}\right)$ é a probabilidade no instante $k$ de que, dadas as observações $\mathbf{x}$ e a informação a respeito do estado do canal $\hat{\mathbf{h}}$, a transição do estado $\sigma_{k}$ para 0 estado $\sigma_{k+1}$ na supertreliça esteja associada com a entrada $u(k)=u^{i}$ no codificador.

Seguindo [27], pode-se definir

$$
\begin{aligned}
& P\left(u(k)=u^{i}, \sigma_{k}, \sigma_{k+1} \mid \mathbf{x}, \hat{\mathbf{h}}\right)= \\
& \quad \lambda \alpha_{k}\left(\sigma_{k}\right) \gamma_{k}^{i}\left(\sigma_{k}, \sigma_{k+1}, \mathbf{x}_{k}\right) \beta_{k+1}\left(\sigma_{k+1}\right),
\end{aligned}
$$

onde $\lambda$ é um coeficiente de normalização tal que

$$
\lambda \sum_{i} \sum_{\sigma_{k}} \sum_{\sigma_{k+1}} P\left(u(k)=u^{i}, \sigma_{k}, \sigma_{k+1} \mid \mathbf{x}\right)=1 .
$$

As recursões $\alpha_{k}$ e $\beta_{k}$ são definidas por:

$$
\alpha_{k+1}\left(\sigma_{k+1}\right)=\sum_{\sigma_{k}} \alpha_{k}\left(\sigma_{k}\right) \gamma_{k}\left(\sigma_{k}, \sigma_{k+1}, \mathbf{x}_{k}\right)
$$

e

$$
\beta_{k}\left(\sigma_{k}\right)=\sum_{\sigma_{k+1}} \beta_{k+1}\left(\sigma_{k+1}\right) \gamma_{k}\left(\sigma_{k}, \sigma_{k+1}, \mathbf{x}_{k}\right),
$$

onde

$$
\gamma_{k}\left(\sigma_{k}, \sigma_{k+1}, \mathbf{x}_{k}\right)=\sum_{i} \gamma_{k}^{i}\left(\sigma_{k}, \sigma_{k+1}, \mathbf{x}_{k}\right)
$$

A probabilidade conjunta $\gamma_{k}^{i}\left(\sigma_{k}, \sigma_{k+1}, \mathbf{x}_{\mathbf{k}}\right)$ é dada por:

$$
\gamma_{k}^{i}\left(\sigma_{k}, \sigma_{k+1}, \mathbf{x}_{\mathbf{k}}\right)=p\left(\mathbf{x}_{k} \mid \sigma_{k}, u^{i}, \hat{\mathbf{h}}\right) P\left(u(k)=u^{i}\right)
$$

onde

$$
\begin{aligned}
& p\left(\mathbf{x}_{k} \mid \sigma_{k}, u^{i}, \hat{\mathbf{h}}\right)=\pi^{-M} N_{0}^{-1} \\
& \quad \cdot \exp \left[-\left(\mathbf{x}_{k}-\mathbf{S}_{k} \hat{\mathbf{h}}_{k}\right)^{H} N_{0}^{-1}\left(\mathbf{x}_{k}-\mathbf{S}_{k} \hat{\mathbf{h}}_{k}\right)\right]
\end{aligned}
$$

é a função densidade de probabilidade dos dados recebidos $\mathbf{x}_{k}$, dados a transição de estados definida por $\left(\sigma_{k}, u^{i}\right)$ e o estado atual do canal $\hat{\mathbf{h}}$, enquanto que $P\left(u(k)=u^{2}\right)$ é a probabilidade-a-priori do símbolo de informação $u^{i}$ no instante $k$.

Através das recursões definidas anteriormente, pode-se reescrever as APP's definidas em (18) como:

$$
\begin{gathered}
P\left(u(k)=u^{i} \mid \mathbf{x}, \hat{\mathbf{h}}\right)=\lambda \sum_{\sigma_{k}} \sum_{\sigma_{k+1}}\left[\alpha_{k}\left(\sigma_{k}\right)\right. \\
\left.\gamma_{k}^{i}\left(\sigma_{k}, \sigma_{k+1}, \mathbf{x}_{k}\right) \beta_{k+1}\left(\sigma_{k+1}\right)\right] .
\end{gathered}
$$

Essa equação é útil para decodificação. Porém, para realimentar o estimador do canal, é necessário definir as APP's dos símbolos transmitidos por cada uma das $N$ antenas:

$$
\begin{aligned}
& P\left(s^{n}(k)=s^{i} \mid \mathbf{x}, \hat{\mathbf{h}}\right)= \\
& \sum_{\sigma_{k}} \sum_{\sigma_{k+1}} P\left(s^{n}(k)=s^{i}, \sigma_{k}, \sigma_{k+1} \mid \mathbf{x}, \hat{\mathbf{h}}\right),
\end{aligned}
$$

onde $P\left(s^{n}(k)=s^{i}, \sigma_{k}, \sigma_{k+1} \mid \mathbf{x}, \hat{\mathbf{h}}\right)$ é a probabilidade no instante $k$ de que, dados o sinal recebido $\mathbf{x}$ e o estado do canal $\hat{\mathbf{h}}$, a transição do estado $\sigma_{k}$ para o estado $\sigma_{k+1}$ esteja associada com a transmissão do símbolo $s^{n}(k)=s^{i}$ pela antena $n$.

Seguindo o mesmo procedimento acima, obtém-se:

$$
\begin{aligned}
& P\left(s^{n}(k)=s^{i}, \sigma_{k}, \sigma_{k+1} \mid \mathbf{x}, \hat{\mathbf{h}}\right)= \\
& \mu \alpha_{k}\left(\sigma_{k}\right) \gamma_{n, k}^{i}\left(\sigma_{k}, \sigma_{k+1}, \mathbf{x}_{k}\right) \beta_{k+1}\left(\sigma_{k+1}\right),
\end{aligned}
$$

onde $\mu$ é um fator de normalização tal qual $\lambda$ e a probabilidade conjunta $\gamma_{n, k}^{i}\left(\sigma_{k}, \sigma_{k+1}, \mathbf{x}_{k}\right)$ é dada por:

$$
\gamma_{n, k}^{i}\left(\sigma_{k}, \sigma_{k+1}, \mathbf{x}_{\mathbf{k}}\right)=p\left(\mathbf{x}_{k} \mid \sigma_{k}, u^{i}, \hat{\mathbf{h}}\right) P\left(s^{n}(k)=s^{i}\right)
$$

onde $P\left(s^{n}(k)=s^{i}\right)$ é a probabilidade-a-priori dos símbolos $s^{n}(k)=s^{i}$ transmitidos pela antena $n$ no instante $k$.

Finalmente, pode-se reescrever as APP's dos símbolos transmitidos pela antena $n$ como:

$$
\begin{gathered}
P\left(s^{n}(k)=s^{i} \mid \mathbf{x}, \hat{\mathbf{h}}\right)=\mu \sum_{\sigma_{k}} \sum_{\sigma_{k+1}}\left[\alpha_{k}\left(\sigma_{k}\right)\right. \\
\left.\cdot \gamma_{n, k}^{i}\left(\sigma_{k}, \sigma_{k+1}, \mathbf{x}_{k}\right) \beta_{k+1}\left(\sigma_{k+1}\right)\right] .
\end{gathered}
$$




\subsection{TRELIÇAS SEPARADAS}

Nesse segundo método, considera-se um processo em dois estágios para detecção e decodificação. No primeiro passo, realiza-se apenas a detecção (equalização) utilizando uma versão modificada do algoritmo BCJR [26] para modulação codificada espaço-temporal [27] através da treliça que representa o canal, com $\left(m^{N}\right)^{D-1}$ estados [13]. Na seqüência, realiza-se decodificação, também usando um algoritmo BCJR modificado para modulação codificada espaçotemporal, mas agora sobre a treliça do código. Note que nesse caso se utiliza um entrelaçador de canal antes da transmissão, e informação extrínseca é trocada entre os dois estágios, sendo então usada como informação-a-priori.

\subsubsection{DETECÇÃO}

A solução de MAP do detector para a seqüência transmitida $s(k)$ (após o entrelaçamento), dadas as observações $\mathbf{x}$, é

$$
s(k)=\arg \max _{i}\left(P\left(s^{n}(k)=s^{i}\right) \mid \mathbf{x}, \hat{\mathbf{h}}\right),
$$

onde $P\left(s^{n}(k)=s^{i} \mid \mathbf{x}, \hat{\mathbf{h}}\right)$ é a APP do símbolo $s^{n}(k)=s^{i}$ a ser transmitido pela antena $n$ no instante $k$, com $i \in$ $\{0,1, \cdots, m-1\}$, e $\hat{\mathbf{h}}$ é a estimativa atual do canal. Essas APP's podem ainda serem expressas como:

$$
\begin{aligned}
& P\left(s^{n}(k)=s^{i} \mid \mathbf{x}, \hat{\mathbf{h}}\right)= \\
& \quad \sum_{\sigma_{k}} \sum_{\sigma_{k+1}} P\left(s^{n}(k)=s^{i}, \sigma_{k}, \sigma_{k+1} \mid \mathbf{x}, \hat{\mathbf{h}}\right),
\end{aligned}
$$

onde $P\left(s^{n}(k)=s^{i}, \sigma_{k}, \sigma_{k+1} \mid \mathbf{x}, \hat{\mathbf{h}}\right)$ é a probabilidade de que, no instante $k$, dados os símbolos recebidos $\mathbf{x} \mathrm{e}$ a atual estimativa do canal $\hat{\mathbf{h}}$, a transição entre os estados $\sigma_{k}$ e $\sigma_{k+1}$, na treliça do canal, esteja associada com a transmissão do símbolo $s^{n}(k)=s^{i}$ pela antena $n$.

De maneira análoga à seção anterior, define-se:

$$
\begin{aligned}
& P\left(s^{n}(k)=s^{i}, \sigma_{k}, \sigma_{k+1} \mid \mathbf{x}, \hat{\mathbf{h}}\right)= \\
& \quad \mu \alpha_{k}\left(\sigma_{k}\right) \gamma_{n, k}^{i}\left(\sigma_{k}, \sigma_{k+1}, \mathbf{x}_{k}\right) \beta_{k+1}\left(\sigma_{k+1}\right),
\end{aligned}
$$

onde $\mu$ é um coeficiente de normalização e as recursões $\alpha_{k} \mathrm{e}$ $\beta_{k}$ são definidas como (22) e (23). Porém, nesse caso:

$$
\begin{aligned}
& \gamma_{k}\left(\sigma_{k}, \sigma_{k+1}, \mathbf{x}_{k}\right)=p\left(\mathbf{x}_{k} \mid \sigma_{k}, \sigma_{k+1}, \hat{\mathbf{h}}\right) \\
& \quad \prod_{n} \sum_{i} P_{a}\left(s^{n}(k)=s^{i}, \sigma_{k}, \sigma_{k+1} \mid \mathbf{x}, \hat{\mathbf{h}}\right),
\end{aligned}
$$

e

$$
\begin{gathered}
\gamma_{n, k}^{i}\left(\sigma_{k}, \sigma_{k+1}, \mathbf{x}_{k}\right)=p\left(\mathbf{x}_{k} \mid \sigma_{k}, \sigma_{k+1}, \hat{\mathbf{h}}\right) \\
\cdot P_{a}\left(s^{n}(k)=s^{i}, \sigma_{k}, \sigma_{k+1} \mid \mathbf{x}, \hat{\mathbf{h}}\right),
\end{gathered}
$$

onde $P_{a}\left(s^{n}(k)=s^{i}, \sigma_{k}, \sigma_{k+1} \mid \mathbf{x}, \hat{\mathbf{h}}\right)$ é a probabilidade-apriori de que, no instante $k$, dados $\mathbf{x}$ e $\hat{\mathbf{h}}$, a transição do estado $\sigma_{k}$ para o estado $\sigma_{k+1}$ na treliça do canal esteja associada com a transmissão do símbolo $s^{n}(k)=s^{i}$ pela antena $n$. Pode-se calcular essas probabilidades-a-priori através de:

$$
\begin{aligned}
& P_{a}\left(s^{n}(k)=s^{i}, \sigma_{k}, \sigma_{k+1} \mid \mathbf{x}, \hat{\mathbf{h}}\right)= \\
& \quad P_{a}\left(s^{n}(k)=s^{i} \mid \mathbf{x}, \hat{\mathbf{h}}\right) \cdot \tau,
\end{aligned}
$$

onde $\tau=1$ se a transição $\left(\sigma_{k}, \sigma_{k+1}\right)$ na treliça do canal estiver rotulada com $s^{n}=s^{i}$. Em caso contrário, $\tau=0$. $P_{a}\left(s^{n}(k)=s^{i} \mid \mathbf{x}, \hat{\mathbf{h}}\right)$ é a informação-a-priori obtida do decodificador.

Por fim, assim como em (26),

$$
\begin{aligned}
& p\left(\mathbf{x}_{k} \mid \sigma_{k}, \sigma_{k+1}, \hat{\mathbf{h}}\right)=\pi^{-M} N_{0}^{-1} \\
& \quad \cdot \exp \left[-\left(\mathbf{x}_{k}-\mathbf{S}_{k} \hat{\mathbf{h}}_{k}\right)^{H} N_{0}^{-1}\left(\mathbf{x}_{k}-\mathbf{S}_{k} \hat{\mathbf{h}}_{k}\right)\right]
\end{aligned}
$$

é a função densidade de probabilidade dos dados recebidos $\mathbf{x}_{k}$, dadas agora a matriz $\mathbf{S}_{k}$ associada com a transição $\left(\sigma_{k}, \sigma_{k+1}\right)$ na treliça do canal e a estimativa atual do canal h.

Com essas definições, pode-se reescrever as APP's em (32) da seguinte maneira:

$$
\begin{gathered}
P\left(s^{n}(k)=s^{i} \mid \mathbf{x}, \hat{\mathbf{h}}\right)=\mu \sum_{\sigma_{k}} \sum_{\sigma_{k+1}}\left[\alpha_{k}\left(\sigma_{k}\right)\right. \\
\left.\cdot \gamma_{n . k}^{i}\left(\sigma_{k}, \sigma_{k+1}, \mathbf{x}_{k}\right) \beta_{k+1}\left(\sigma_{k+1}\right)\right] .
\end{gathered}
$$

Determina-se a informação extrínseca a ser passada para o decodificador, como em [10], através da relação

$$
\begin{aligned}
P\left(s^{n}(k)=s^{i} \mid \mathbf{x}, \hat{\mathbf{h}}\right)=\pi & \left(P_{e}\left(s^{n}(k)=s^{i} \mid \tilde{\mathbf{x}}, \hat{\mathbf{h}}\right)\right) \\
& \cdot P_{a}\left(s^{n}(k)=s^{i} \mid \mathbf{x}, \hat{\mathbf{h}}\right),
\end{aligned}
$$

onde $\pi(\bullet)$ corresponde à operação de entrelaçamento e $\tilde{\mathbf{x}}$ é a versão desentrelaçada $\mathbf{d e} \mathbf{x}$.

\subsubsection{DECODIFICAÇÃO}

A decodificação é realizada de forma bem similar à detecção. A diferença é que agora deve-se também disponibilizar as APP's da sequiência de entrada do codificador.

Novamente, busca-se:

$$
u(k)=\arg \max _{i} P\left(u(k)=u^{i} \mid \tilde{\mathbf{x}}, \hat{\mathbf{h}}\right),
$$

onde $P\left(u(k)=u^{i} \mid \tilde{\mathbf{x}}, \hat{\mathbf{h}}\right)$ é a APP dos símbolos de entrada $u(k)=u^{i}$, que pode ser reescrita como:

$$
\begin{aligned}
& P\left(u(k)=u^{i} \mid \tilde{\mathbf{x}}, \hat{\mathbf{h}}\right)= \\
& \quad \sum_{\sigma_{k}} \sum_{\sigma_{k+1}} P\left(u(k)=u^{i}, \sigma_{k}, \sigma_{k+1} \mid \tilde{\mathbf{x}}, \hat{\mathbf{h}}\right),
\end{aligned}
$$

onde $P\left(u(k)=u^{i}, \sigma_{k}, \sigma_{k+1} \mid \tilde{\mathbf{x}}, \hat{\mathbf{h}}\right)$ é a probabilidade no instante $k$ de que, dadas a versão desentrelaçada dos dados recebidos $\tilde{\mathbf{x}}$ e a estimativa atual do canal $\hat{\mathbf{h}}$, a transição do estado $\sigma_{k}$ para o estado $\sigma_{k+1}$ na treliça do código esteja associada com a entrada $u(k)=u^{i}$.

Seguindo o padrão das seções anteriores, pode-se escrever:

$$
\begin{aligned}
& P\left(u(k)=u^{i}, \sigma_{k}, \sigma_{k+1} \mid \tilde{\mathbf{x}}, \hat{\mathbf{h}}\right)= \\
& \quad \lambda \alpha_{k}\left(\sigma_{k}\right) \gamma_{k}^{i}\left(\sigma_{k}, \sigma_{k+1}, \tilde{\mathbf{x}}_{k}\right) \beta_{k+1}\left(\sigma_{k+1}\right),
\end{aligned}
$$

onde $\lambda$ é um fator de normalização e as recursões $\alpha_{k}$ e $\beta_{k}$ são definidas do modo usual, com a diferença que aqui

$$
\gamma_{k}\left(\sigma_{k}, \sigma_{k+1}, \tilde{\mathbf{x}}_{k}\right)=\sum_{i} \gamma_{k}^{i}\left(\sigma_{k}, \sigma_{k+1}, \tilde{\mathbf{x}}_{k}\right)
$$


A probabilidade conjunta $\gamma_{k}^{i}\left(\sigma_{k}, \sigma_{k+1}, \tilde{\mathbf{x}}_{\mathbf{k}}\right)$ é dada por:

$$
\begin{aligned}
& \gamma_{k}^{i}\left(\sigma_{k}, \sigma_{k+1}, \tilde{\mathbf{x}}_{\mathbf{k}}\right)= \\
& \prod_{n} \sum_{i^{\prime}} P_{a}\left(s^{n}(k)=s^{i^{\prime}}, \sigma_{k}, \sigma_{k+1}, u^{i} \mid \tilde{\mathbf{x}}, \hat{\mathbf{h}}\right),
\end{aligned}
$$

onde $P_{a}\left(s^{n}(k)=s^{i^{\prime}}, \sigma_{k}, \sigma_{k+1}, u^{i} \mid \tilde{\mathbf{x}}, \hat{\mathbf{h}}\right)$ é a probabilidadea-priori de que, no instante $k$, dados $\tilde{\mathbf{x}} \mathrm{e} \hat{\mathbf{h}}$, a transição entre os estados $\sigma_{k}$ e $\sigma_{k+1}$ na treliça do código, produzida pelo símbolo de informação $u^{i}$, esteja associada com a transmissão do símbolo $s^{n}(k)=s^{i^{\prime}}$ pela antena $n$. Note que, para o cálculo da probabilidade acima, necessita-se da versão desentrelaçada de (40) e da treliça do STC, de modo similar ao que foi feito em (37).

Por fim, calcula-se as APP's em (41):

$$
\begin{gathered}
P\left(u(k)=u^{i} \mid \tilde{\mathbf{x}}, \hat{\mathbf{h}}\right)=\lambda \sum_{\sigma_{k}} \sum_{\sigma_{k+1}}\left[\alpha_{k}\left(\sigma_{k}\right)\right. \\
\left.\cdot \gamma_{k}^{i}\left(\sigma_{k}, \sigma_{k+1}, \tilde{\mathbf{x}}_{k}\right) \beta_{k+1}\left(\sigma_{k+1}\right)\right] .
\end{gathered}
$$

Assim, como em (27), a equação (46) é útil para a decodificação. Porém, para realimentar o estimador de canal, é necessário que se defina a versão desentrelaçada das APP's dos símbolos transmitidos por cada uma das $N$ antenas:

$$
\begin{aligned}
& P\left(s^{n}(k)=s^{i} \mid \tilde{\mathbf{x}}, \hat{\mathbf{h}}\right)= \\
& \quad \sum_{\sigma_{k}} \sum_{\sigma_{k+1}} P\left(s^{n}(k)=s^{i}, \sigma_{k}, \sigma_{k+1} \mid \tilde{\mathbf{x}}, \hat{\mathbf{h}}\right),
\end{aligned}
$$

onde

$$
\begin{aligned}
& P\left(s^{n}(k)=s^{i}, \sigma_{k}, \sigma_{k+1} \mid \tilde{\mathbf{x}}, \hat{\mathbf{h}}\right)= \\
& \quad \mu \alpha_{k}\left(\sigma_{k}\right) \gamma_{n, k}^{i}\left(\sigma_{k}, \sigma_{k+1}, \tilde{\mathbf{x}}_{k}\right) \beta_{k+1}\left(\sigma_{k+1}\right)
\end{aligned}
$$

$\mu$ é um fator de normalização; as recursões são definidas como usualmente e a probabilidade conjunta $\gamma_{n, k}^{i}\left(\sigma_{k}, \sigma_{k+1}, \mathbf{x}_{k}\right)$ é

$$
\gamma_{n, k}^{i}\left(\sigma_{k}, \sigma_{k+1}, \tilde{\mathbf{x}}_{k}\right)=P_{a}\left(s^{n}(k)=s^{i}, \sigma_{k}, \sigma_{k+1} \mid \tilde{\mathbf{x}}, \hat{\mathbf{h}}\right) .
$$

Assim:

$$
\begin{gathered}
P\left(s^{n}(k)=s^{i} \mid \tilde{\mathbf{x}}, \hat{\mathbf{h}}\right)=\mu \sum_{\sigma_{k}} \sum_{\sigma_{k+1}}\left[\alpha_{k}\left(\sigma_{k}\right)\right. \\
\left.\cdot \gamma_{n, k}^{i}\left(\sigma_{k}, \sigma_{k+1}, \tilde{\mathbf{x}}_{k}\right) \beta_{k+1}\left(\sigma_{k+1}\right)\right] .
\end{gathered}
$$

Pode-se calcular a informação extrínseca a ser passada para o detector através da relação

$$
\begin{aligned}
P\left(s^{n}(k)=s^{i} \mid \tilde{\mathbf{x}}, \hat{\mathbf{h}}\right)= & \pi^{-1}\left(P_{e}\left(s^{n}(k)=s^{i} \mid \mathbf{x}, \hat{\mathbf{h}}\right)\right) \\
& \cdot P_{a}\left(s^{n}(k)=s^{i} \mid \tilde{\mathbf{x}}, \hat{\mathbf{h}}\right),
\end{aligned}
$$

onde $\pi^{-1}(\bullet)$ corresponde à operação inversa do entrelaçamento.

\section{ESTIMAÇÃO, DETECÇÃO E DECODIFICAÇÃO COMBINADAS}

A combinação dos três processos (estimação do canal, detecção/decodificação e estimação da variância) é feita de

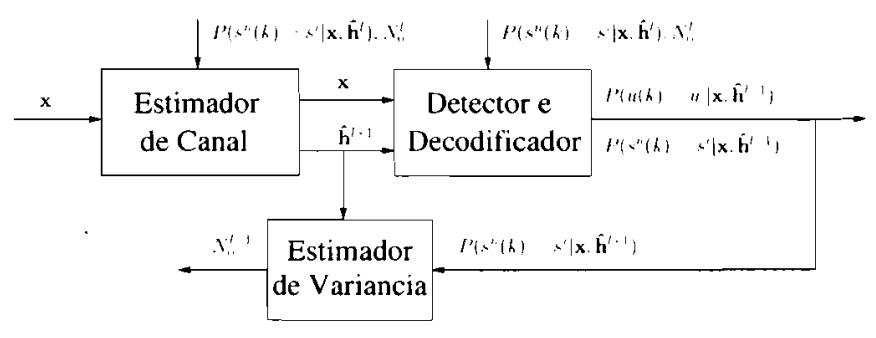

Figura 2. Diagrama de blocos mostrando a interação dos três estágios do receptor.

forma iterativa. Cada iteração $l$ consiste em três passos. $O$ primeiro passo produz uma nova estimativa do canal, $\hat{\mathbf{h}}^{l+1}$, através do algoritmo EM. Este, por sua vez, utiliza tanto as APP's dos símbolos transmitidos, $P\left(s^{n}(k)=s^{i} \mid \mathbf{x}, \hat{\mathbf{h}}^{l}\right)$, fornecidas pelo detector/decodificador, como a estimativa atual da variância do ruído, $\hat{N}_{0}^{l}$, ambas obtidas após a iteração $l-1$. No segundo passo, o detector/decodificador, que pode ser implementando através da supertreliça ou das treliças separadas, produz um novo conjunto de APP's, $P\left(s^{n}(k)=\right.$ $\left.s^{i} \mid \mathbf{x}, \hat{\mathbf{h}}^{l+1}\right)$, com base na estimativa atual do canal, $\hat{\mathbf{h}}^{l+1}$, produzida no primeiro passo da iteração $l$, e na estimativa atual da variância do ruído, $\hat{N}_{0}^{l}$, produzida ao final da iteração $l-1$. Esse novo conjunto de APP's e a nova estimativa do canal são usados no terceiro e último passo da iteração $l$, onde se obtém a nova estimativa da variância do ruído, $\hat{N}_{0}^{l+1}$. A Figura 2 apresenta um diagrama de blocos que resume as interações entre os três estágios do receptor iterativo.

Ao final do segundo passo da última iteração, $l_{f}$, o detector/decodificador produz as APP's dos dados de entrada do codificador, $P\left(u(k)=u^{i} \mid \mathbf{x}, \hat{\mathbf{h}}^{l_{s}}\right)$, as quais são utilizadas na decisão final sob o critério de MAP.

Finalmente, na estratégia semicega adotada neste trabalho $T_{r}$ símbolos são conhecidos dentro de um bloco de comprimento $L$. Essa perda na taxa líquida de informação é levada em conta nas simulações, onde a SNR efetiva a ser considerada é dada por:

$$
\mathrm{SNR}_{\mathrm{eff}}=\mathrm{SNR} \times \frac{L-T_{r}}{L}
$$

onde $\mathrm{SNR}=\frac{N \times \Phi_{\Sigma}}{N_{0}}$. Com essa definição é possível otimizar o desempenho dos receptores propostos em função do número de símbolos conhecidos dentro de um bloco' ${ }^{1}$.

\section{SUPERTRELIÇA VERSUS TRELIÇAS SEPARADAS}

Nesta seção, compara-se os dois métodos apresentados anteriormente (supertreliça e treliças separadas) em termos de complexidade de treliça, nível de diversidade e BER.

\footnotetext{
${ }^{1}$ Note que sem essa normalização da SNR, obtería-se um desempenho monotonicamente crescente em função de $T_{r}$, o que não refletiria a relação custo-benefício entre vazão e desempenho característica de métodos semicegos.
} 


\subsection{COMPLEXIDADE DE TRELIÇA E NÍVEL DE DIVERSIDADE}

McEliece e Lin definiram em [25] a complexidade de treliça para um código convolucional, a qual está diretamente relacionada com o esforço computacional requerido por um algoritmo do tipo Viterbi [28] ou BCJR [26] para decodificar um bit e é função do módulo de treliça [25] para o código em questão. Muito embora a complexidade de treliça ter sido definida para códigos binários, aplica-se esse conceito no caso de STC's. Na realidade, a metodologia empregada concentra-se unicamente na contagem de ramos dado um certo módulo de treliça, não levando em conta o número de bits associado com o rótulo de cada ramo, uma vez que este será o mesmo para todos os casos considerados neste trabalho.

Em geral, se o módulo de treliça para o STC tem $\sigma_{\text {code }}$ estados e $e_{\text {code }}$ ramos saindo de cada estado, então o módulo para a supertreliça, a qual combina o modelo Markoviano para o canal com IES com a treliça do STC, tem

$$
\left(\sigma_{\text {cade }} \times m^{D-1}\right) \times e_{\text {code }}
$$

ramos.

Por outro lado, o módulo para as treliças separadas tem uma contagem de ramos dada por:

$$
\left(\left(m^{N}\right)^{D-1} \times m^{N}\right)+\left(\sigma_{\text {code }} \times e_{\text {code }}\right) .
$$

Uma vez que $\left(m^{N}\right)^{D}$ é, em geral, maior do que $\left(\sigma_{\text {code }} \times\left(m^{D-1}-1\right)\right) \times e_{\text {code }}$, pode-se afirmar que a supertreliça demanda, geralmente, menor esforço computacional do que as treliças separadas.

Por exemplo, considere o STC 4-PSK com 8 estados projetado por Tarokh et al [3], $N=2$ e $D=2$. Construindo a supertreliça para esse caso, cada estado da treliça do código é dividido em $m^{D-1}=4$ estados. Assim, o módulo da treliça resultante, que pode ser visto na Figura 3, tem uma contagem de ramos de $32 \times 4=128$.

Para o caso das treliças separadas, constrói-se primeiramente a treliça para o canal, com $\left(m^{N}\right)^{D-1}=\left(4^{2}\right)^{1}=16$ estados e $m^{N}=4^{2}=16$ ramos saindo de cada estado, cujo módulo pode ser visto na Figura 4, e que tem $16 \times 16=256$ ramos. Em seguida, considera-se o módulo de treliça para o STC, mostrado na Figura 5, que possui $8 \times 4=32$ ramos. Assim, a contagem de ramos considerando-se os dois módulos é de $256+32=288$ ramos, valor maior do que o dobro da contagem para a supertreliça. Portanto, de acordo com [25], o esforço computacional requerido pela supertreliça para decodificar um bit é menor do que a metade do esforço requerido pelas treliças separadas.

A Tabela 1 lista a contagem de ramos da supertreliça e das treliças separadas, para os casos dos STC's 4-PSK com $\{4,8,16\}$ estados, 8-PSK com $\{8,16,32\}$ estados, $D=$ $\{2,3\}$ e $N=2$ antenas transmissoras. Analisando a tabela, é possivel afirmar que a supertreliça é menos complexa do que as treliças separadas para todos os doze casos estudados e que essa vantagem se acentua com o aumento do comprimento da interferência e da eficiência espectral.

Entretanto, ao se utilizar a supertreliça, é possível que não se atinga o mesmo grau de diversidade que poderia ser

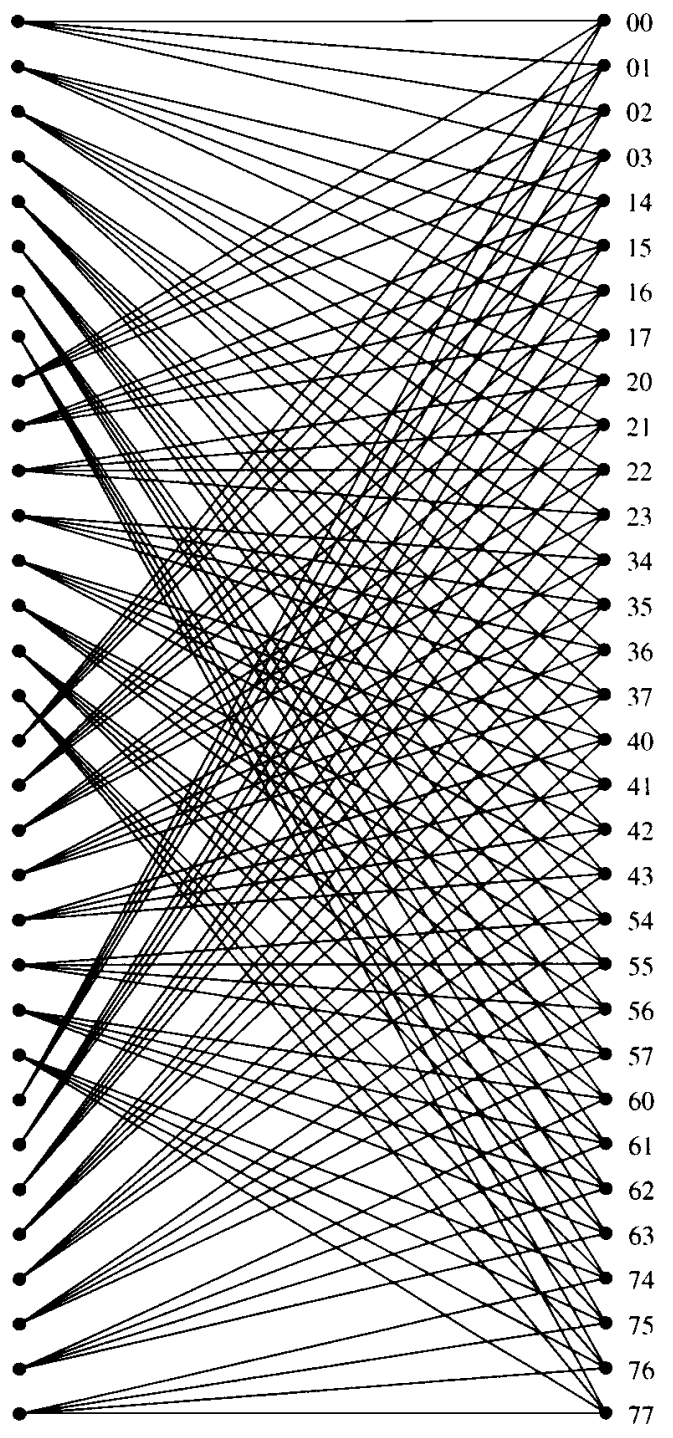

Figura 3. Supertreliça para detecção e decodificação conjunta, para o STC 4-PSK com 8 estados, $N=2$ e $D=2$. Os símbolos à direita representam os estados da treliça.

atingido com a utilização de treliças separadas. Em [24, Teorema 1] foi mostrado que quando um entrelaçador de canal não está presente (como no caso da supertreliça), para se atingir uma taxa de transmissão de $m$ bits/símbolo e um grau de diversidade $r$ por antena receptora, o STC precisa ter ao menos $2^{m(r-D)}$ estados. Por outro lado, em [24, Teorema 2] foi mostrado que, quando um entrelaçador de canal é usado (como no caso das treliças separadas), para se atingir uma taxa de transmissão de $m$ bits/símbolo e um grau de diversidade $r$ por antena receptora, o STC precisa dispor de ao menos $2^{m\left(\frac{r}{\nu}-1\right)}$ estados, o que, para um canal seletivo em freqüência, é sempre menor do que $2^{m(r-D)}$

Por exemplo, para o STC 4-PSK com 8 estados, $N=2$ e $D=2$, como considerado acima, no caso da supertreliça (onde um entrelaçador de canal não é usado), o nível de diversidade que pode ser atingido é

$$
r=\frac{3}{2}+2=3.5
$$

enquanto que no caso das treliças separadas (onde um 


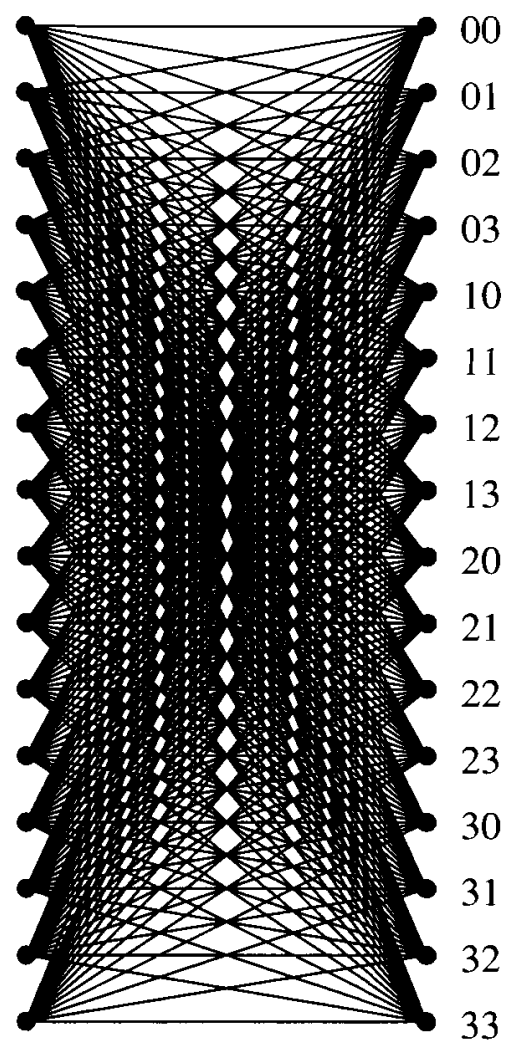

Figura 4. Treliça para o canal com IES, onde $m=4, N=2$ e $D=2$. Os símbolos à direita representam os estados da treliça. Os rótulos dos ramos são complexos e função dos coeficientes do canal.

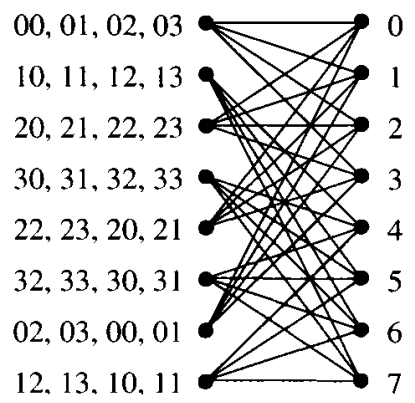

Figura 5. Treliça para o código 4-PSK com 8 estados para $N=2$ antenas transmissoras, projetado por Tarokh $e t$ al. Os símbolos à esquerda representam os rótulos dos ramos e os símbolos à direita correspondem aos estados da treliça.

entrelaçador de canal é utilizado), a diversidade completa $(r=4)$ pode ser atingida.

A Tabela 2 lista o nível de diversidade que pode ser atingido pelos métodos propostos, para os mesmo casos considerados na Tabela 1. Pela análise dos dados fica claro que, para os doze casos estudados, a supertreliça atinge um grau de diversidade menor do que as treliças separadas, com a única exceção do caso do STC 4-PSK com 16 estados e $D=2$, em que os dois métodos atingem o mesmo grau de diversidade.

Note que nesta seção foi considerada a complexidade de treliça para o módulo, a qual está diretamente relacionada com o esforço computacional para se realizar uma iteração. Entretanto, a complexidade total de treliça de-

\begin{tabular}{||c||c|c|c||}
\hline \hline \multicolumn{5}{|c|}{ Modulação 4-PSK } \\
\hline$D=2$ & $\sigma_{\text {code }}=4$ & $\sigma_{\text {code }}=8$ & $\sigma_{\text {code }}=16$ \\
\hline Supertreliça & 64 & 128 & 256 \\
Separadas & 272 & 288 & 320 \\
\hline \hline$D=3$ & $\sigma_{\text {code }}=4$ & $\sigma_{\text {code }}=8$ & $\sigma_{\text {code }}=16$ \\
\hline Supertreliça & 256 & 512 & 1024 \\
Separadas & 4112 & 4128 & 4160 \\
\hline \multicolumn{4}{|c||}{ Modulação 8-PSK } \\
\hline \hline$D=2$ & $\sigma_{\text {code }}=8$ & $\sigma_{\text {code }}=16$ & $\sigma_{\text {code }}=32$ \\
\hline Supertreliça & 512 & 1024 & 2048 \\
Separadas & 4160 & 4224 & 4352 \\
\hline \hline$D=3$ & $\sigma_{\text {code }}=8$ & $\sigma_{\text {code }}=16$ & $\sigma_{\text {code }}=32$ \\
\hline Supertreliça & 4096 & $\mathbf{8 1 9 2}$ & 16384 \\
Separadas & 262208 & 262272 & 262400 \\
\hline
\end{tabular}

Tabela 1. Contagem de ramos para a supertreliça e para as treliças separadas, considerando-se os STC's 4-PSK com $\sigma_{\text {code }}=\{4,8,16\}$ estados, 8-PSK com $\sigma_{\text {code }}=\{8,16,32\}$ estados, $D=\{2,3\}$ e $N=2$. O número de ramos deixando cada estado da treliça dos códigos é de $e_{\text {code }}=4$ para os códigos 4-PSK e $e_{\text {code }}=8$ para os códigos 8-PSK.

\begin{tabular}{||c||c|c|c||}
\hline \multicolumn{5}{|c|}{ Modulação 4-PSK } \\
\hline$D=2$ & $\sigma_{\text {code }}=4$ & $\sigma_{\text {code }}=8$ & $\sigma_{\text {code }}=16$ \\
\hline Supertreliça & 3 & 3.5 & 4 \\
Separadas & 4 & 4 & 4 \\
\hline \hline$D=3$ & $\sigma_{\text {code }}=4$ & $\sigma_{\text {code }}=8$ & $\sigma_{\text {code }}=16$ \\
\hline Supertreliça & 4 & 4.5 & 5 \\
Separadas & 6 & 6 & 6 \\
\hline \hline \multicolumn{4}{|c||}{ Modulação 8-PSK } \\
\hline \hline$D=2$ & $\sigma_{\text {code }}=8$ & $\sigma_{\text {code }}=16$ & $\sigma_{\text {code }}=32$ \\
\hline Supertreliça & 3 & 3.33 & 3.66 \\
Separadas & 4 & 4 & 4 \\
\hline \hline$D=3$ & $\sigma_{\text {code }}=8$ & $\sigma_{\text {code }}=16$ & $\sigma_{\text {code }}=32$ \\
\hline Supertreliça & 4 & 4.33 & 4.66 \\
Separadas & 6 & 6 & 6 \\
\hline \hline
\end{tabular}

Tabela 2. Nível de diversidade que pode ser atingido pelo receptor usando a supertreliça e para o receptor usando as treliças separadas, para o caso dos STC's 4-PSK com $\sigma_{\text {code }}=$ $\{4,8,16\}$ estados, 8-PSK com $\sigma_{\text {code }}=\{8,16,32\}$ estados, $D=\{2,3\}, N=2$ e $M=1$.

pende do número de iterações que cada receptor (usando a supertreliça ou as treliças separadas) requer para a convergência. Assim, é necessário investigar a taxa de convergência de cada estrutura para que se possa determinar a real diferença de complexidade entre elas, bem como avaliar como os seus diferentes níveis de diversidade se refletem na BER.

\subsection{SIMULAÇÕES COMPUTACIONAIS}

Nesta seção, investiga-se o desempenho dos dois receptores propostos em termos de BER versus SNR. Seguindo o exemplo considerado na seção anterior, considera-se que os dados são codificados utilizando-se o STC 4-PSK com 8 es- 


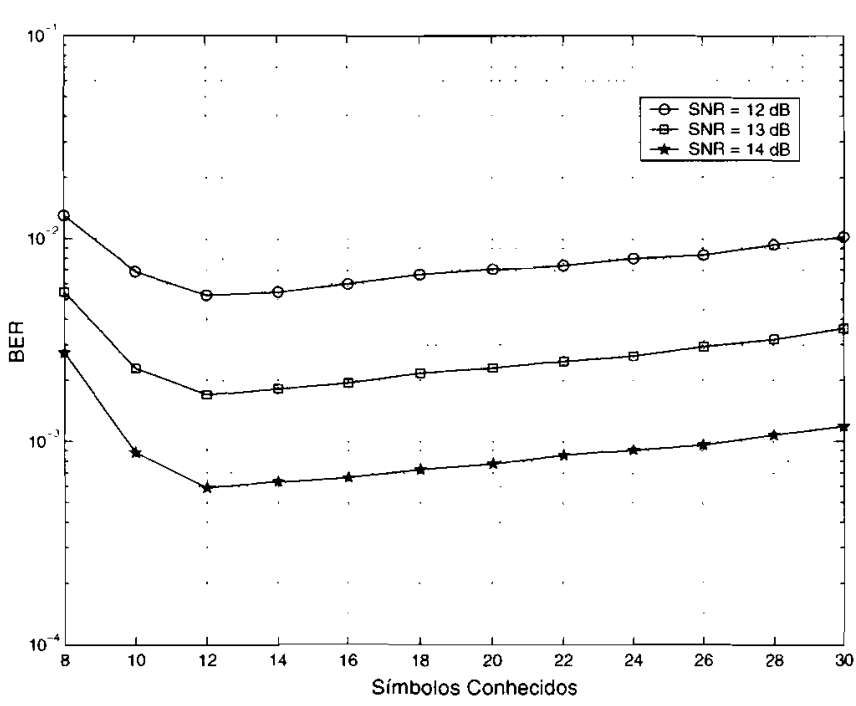

Figura 6. BER ao final de $l^{\prime}=3$ iterações para o receptor semicego usando a supertreliça, versus o número de símbolos conhecidos dentro do bloco, $T_{r}^{\prime}$, para as SNR's $=\{12,13,14\}$ $\mathrm{dB}$, o STC 4-PSK com 8 estados projetado por Tarokh et al, $N=2$ antenas transmissoras, $M=1$ antena receptora e $D=2$

tados projetado por Tarokh et al [3]. Os símbolos codificados são então transmitidos em blocos de $L=130$ símbolos. Nas seguintes simulações, o número de antenas transmissoras é $N=2$, os canais são seletivos em freqüência, $D=2$ e com desvanecimento Rayleigh quase estático, em que os coeficientes de cada um dos $M \times N$ canais têm a mesma variância $\sigma_{d}^{2}=0,5$, são constantes durante um bloco e mudam independentemente de um bloco ao outro ${ }^{2}$. Para o caso das treliças separadas, o entrelaçador de canal utilizado é do tipo matricial, $13 \times 10$ e determinístico.

Note ainda que nas simulações, a variância do ruido é calculada a partir de $\mathrm{SNR}_{\text {eff }}$, a qual é função de $\mathrm{SNR}, L$ e $T_{r}$. Assim, uma vez que a introdução de alguns símbolos conhecidos dentro do bloco induz a uma perda na SNR efetiva, não é necessariamente verdade que aumentar o número de símbolos conhecidos $T_{r}$ levará a uma BER menor. Logo, é necessário otimizar o número de símbolos conhecidos $T_{r}$ para cada um dos dois métodos considerados.

A Figura 6 apresenta um gráfico da BER, depois de três iterações usando a supertreliça para deteç̧ão e decodificação conjunta, versus o número de símbolos conhecidos dentro do bloco $T_{r}$, para diferentes níveis de SNR e $M=1$ antena receptora. Pelos resultados obtidos, pode-se concluir que o número ótimo de símbolos conhecidos dentro do bloco, com respeito à mínima BER, é aproximadamente $T_{r}^{\prime}=12$ símbolos.

Em seguida, compara-se o desempenho do receptor semicego utilizando a supertreliça ao obtido pelo mesmo receptor empregando o conhecimento prévio do canal. A Figura 7 mostra a BER versus a SNR para o caso de $M=1$ antena receptora, após as iterações $l^{\prime}=\{1,2,3\}$ do recep-

${ }^{2}$ Note que canais com comprimento de interferência mais longo sempre podem ser reduzidos a um canal equivalente com comprimento mais curto através de uma pré-filtragem, como explorado em [12].

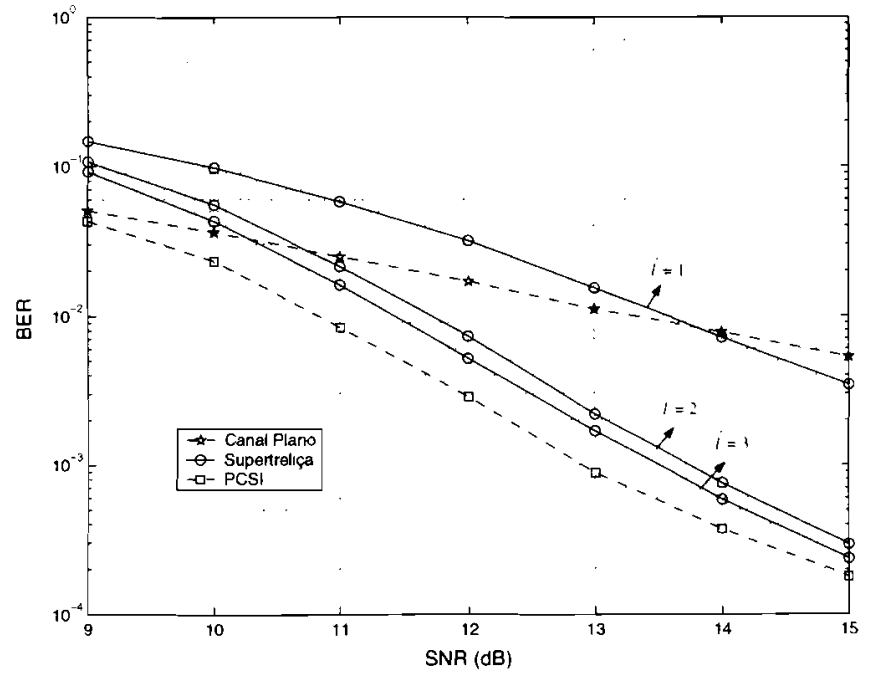

Figura 7. BER versus SNR, para o STC 4-PSK com 8 estados projetado por Tarokh et al, $N=2$ antenas transmissoras, $M=1$ antena receptora, $D=2$ e $T_{r}^{\prime}=12$ símbolos conhecidos dentro do bloco de $L=130$ símbolos. Supertreliça é a BER após $l^{\prime}=\{1,2,3\}$ iterações para o receptor semicego proposto usando uma supertreliça e PCSI é a BER para o receptor usando a supertreliça mas com conhecimento prévio do canal. A BER para o caso do canal plano também é mostrada na figura.

tor semicego usando a supertreliça; na saída de um receptor usando também a supertreliça, mas com conhecimento prévio do canal, e para o caso onde o canal é plano $(D=1)$. Podese concluir que $l^{\prime}=3$ iterações para o receptor semicego usando a supertreliça são suficientes para que seu desempenho fique a apenas $0,5 \mathrm{~dB}$ do caso do receptor com conhecimento prévio do canal. Note também que, após uma SNR um pouco maior do que $10 \mathrm{~dB}$, o receptor semicego utilizando uma supertreliça, graças à diversidade induzida pelo canal com IES, apresenta um desempenho superior ao caso do canal plano.

Na Figura 8, investiga-se novamente a questão do número ótimo de símbolos conhecidos dentro do bloco, mas agora após oito iterações do receptor semicego usando treliças separadas para detecção e decodificação combinadas. Nesse caso, o comprimento ótimo está concentrado na região definida por $T_{r}^{\prime \prime}=[20 ; 30]$ símbolos. Daqui em diante, será utilizado $T_{r}^{\prime \prime}=20$ para não sacrificar em demasia a taxa líquida de informação que pode ser transmitida através do canal.

Assim como no caso da supertreliça, o desempenho do receptor semicego usando treliças separadas será comparado com o do mesmo receptor tendo conhecimento prévio do canal. A Figura 9 apresenta a BER versus a SNR após $l^{\prime \prime}=\{1,2,4,6,8\}$ iterações para o receptor semicego usando treliças separadas; após $l^{\prime \prime}=5$ iterações para o receptor usando treliças separadas, mas com conhecimento prévio do canal, e também para o caso do canal plano. Pode-se notar que para o receptor semicego usando treliças separadas, após uma SNR de $10,5 \mathrm{~dB}$, o efeito de diversidade induzido pelos canais com IES produz uma BER menor do que a BER obtida 


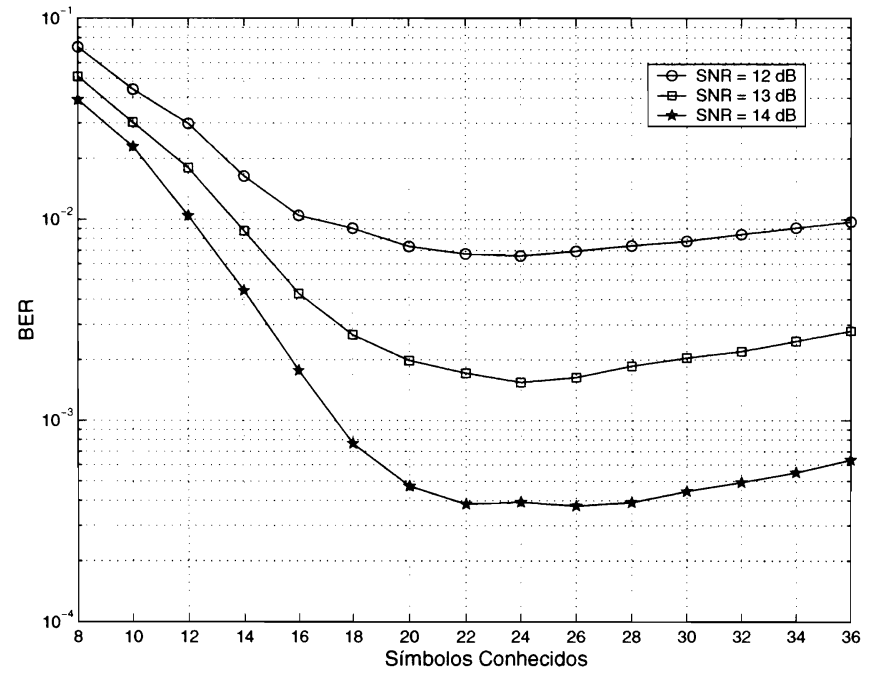

Figura 8. BER ao final de $l^{\prime \prime}=8$ iterações para o receptor semicego usando treliças separadas, versus o número de símbolos conhecidos dentro do bloco, $T_{r}^{\prime \prime}$, para as SNR's = $\{12,13,14\} \mathrm{dB}$, o STC 4-PSK com 8 estados projetado por Tarokh et al, $N=2$ antenas transmissoras, $M=1$ antena receptora e $D=2$.

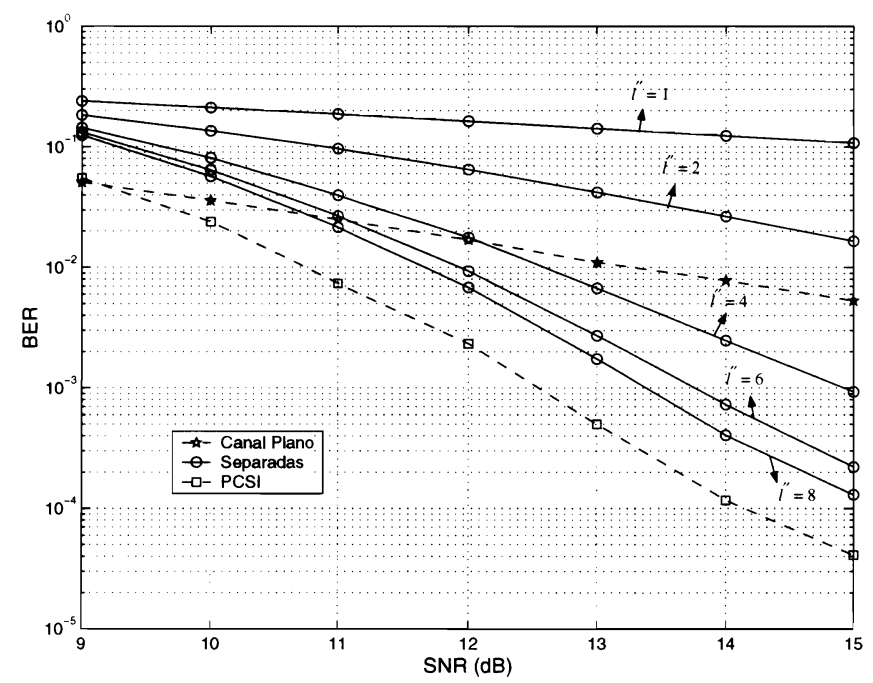

Figura 9. BER versus SNR, para o STC 4-PSK com 8 estados projetado por Tarokh et al, $N=2$ antenas transmissoras, $M=1$ antena receptora, $D=2$ e $T_{r}^{\prime \prime}=20$ símbolos conhecidos dentro do bloco de $L=130$ símbolos. Separadas é a BER após $l^{\prime \prime}=\{1,2,4,6,8\}$ iterações para o receptor semicego proposto usando treliças separadas e PCSI é a BER após $l^{\prime \prime}=5$ iterações para o receptor usando treliças separadas mas com conhecimento prévio do canal. A BER para o caso do canal plano também é mostrada na figura.

no caso de um canal plano, sem IES. Comparado ao receptor com conhecimento prévio do canal, o receptor semicego apresenta uma perda de desempenho de apenas $1 \mathrm{~dB}$.

De acordo com as Figuras 7 e 9, a supertreliça mostrou ser mais do que duas vezes mais rápida do que as treliças separadas em termos de taxa de convergência. Isso pode ser explicado pelo fato de que a supertreliça impõe fortes

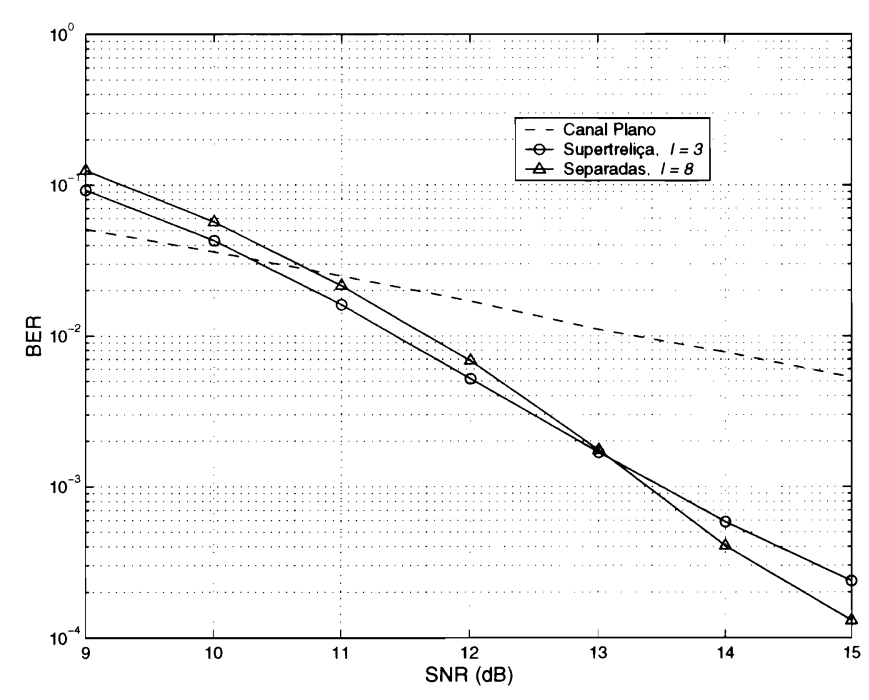

Figura 10. BER versus SNR para o STC 4-PSK com 8 estados projetado por Tarokh et al, $N=2$ antenas transmissoras, $M=1$ antena receptora e $D=2$. Supertreliça é a BER após $l^{\prime}=3$ iterações para o receptor semicego usando uma supertreliça e Separadas é a BER após $l^{\prime \prime}=8$ iterações para o receptor semicego usando treliças separadas. A BEK para o caso de um canal plano também está mostrada na figura.

restrições nas possíveis seqüências transmitidas e, assim, o receptor procura em um espaço muito mais reduzido do que o receptor usando treliças separadas. Com as treliças separadas, a detecção é realizada no espaço irrestrito definido pela eficiência espectral, pelo número de antenas transmissoras e pelo tamanho do bloco, o que reduz consideravelmente a velocidade de convergência. Além disso, a supertreliça necessita de um menor número de símbolos conhecidos dentro do bloco para atingir o seu melhor desempenho, o que garante uma taxa líquida de informação mais alta.

Uma vez que foi determinado o número ótimo de símbolos conhecidos, $T_{r}^{\prime}=12$ e $T_{r}^{\prime \prime}=20$, e o número de iterações necessárias para convergência, $l^{\prime}=3$ e $l^{\prime \prime}=8$, respectivamente para o caso da supertreliça e para o caso das treliças separadas, já se pode comparar os dois esquemas em termos de BER. As Figuras 10 e 11 apresentam em função da SNR e para, respectivamente, $M=1$ e $M=2$ antenas receptoras, a BER após $l^{\prime}=3$ iterações para o receptor semicego usando uma supertreliça e conhecendo $T_{r}^{\prime}=12$ símbolos dentro do bloco; a BER após $l^{\prime \prime}=8$ iterações para o receptor semicego usando treliças separadas e conhecendo $T_{r}^{\prime \prime}=20$ símbolos dentro do bloco e a BER para o caso de um canal plano. Analisando esse resultados, pode-se afirmar que, mesmo com um nível de diversidade um pouco inferior, o receptor iterativo empregando a supertreliça apresenta um desempenho bastante similar ao do receptor usando treliças separadas para a margem de SNR's consideradas.

Por fim, considerando que o receptor é iterativo, a contagem total de ramos (TEC) para o caso da supertreliça é

$$
T E C_{\text {super }}=l^{\prime} \times 128=3 \times 128=384,
$$

enquanto que para o caso das treliças separadas, é igual a

$$
T E C_{s e p}=l^{\prime \prime} \times 288=8 \times 288=2304 .
$$




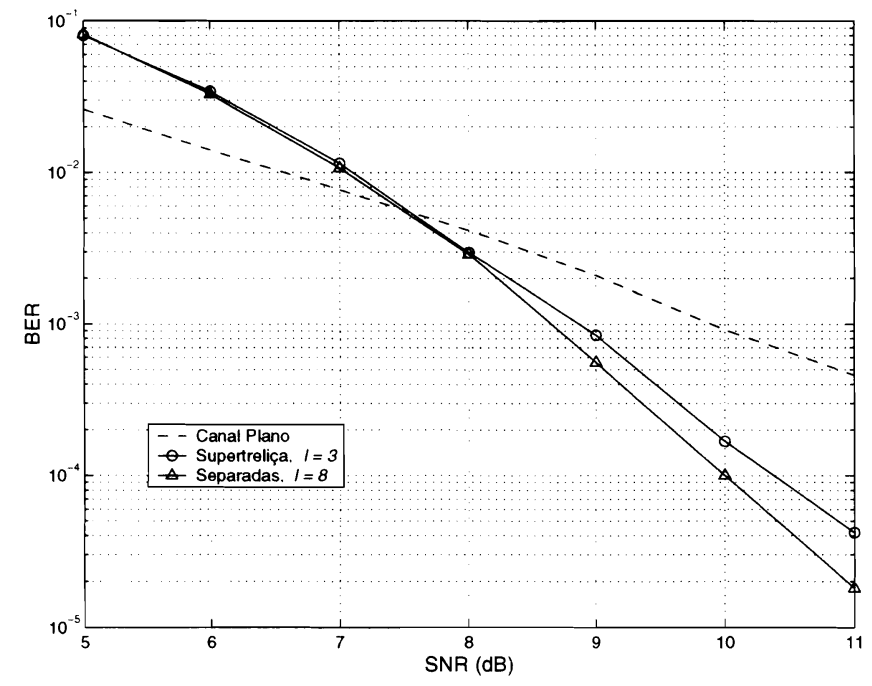

Figura 11. BER versus SNR para o STC 4-PSK com 8 estados projetado por Tarokh et al, $N=2$ antenas transmissoras, $M=2$ antenas receptoras e $D=2$. Supertreliça é a BER após $l^{\prime}=3$ iterações para o receptor semicego usando uma supertreliça, e Separadas é a BER após $l^{\prime \prime}=8$ iterações para o receptor semicego usando treliças separadas. A BER para o caso de um canal plano também está mostrada na figura.

Dessa forma, no exemplo aqui apresentado ${ }^{3}$, o esforço computacional requerido pela supertreliça é seis vezes menor do que pelas treliças separadas, enquanto que a diferença de desempenho ficou em no máximo $0,5 \mathrm{~dB}$.

\section{COMENTÁRIOS FINAIS}

Neste artigo, foram apresentados dois receptores diferentes empregando modulação espaço-temporal para canais de propagação seletivos em freqüência, quase estáticos e desconhecidos. Ambos os receptores operam de forma semicega e utilizam o algoritmo EM para estimar o canal. $\mathrm{O}$ primeiro receptor realiza os processos de detecção e decodificação através do emprego de uma supertreliça (portanto de forma conjunta), enquanto que o segundo utiliza treliças separadas (de forma combinada). Em ambos os casos, o equacionamento é baseado em um algoritmo BCJR modificado para modulação espaço-temporal.

Os dois métodos foram comparados em termos de complexidade de treliça, nível de diversidade e BER. Esse procedimento evidenciou a existência de uma relação custobenefício entre desempenho e complexidade computacional, a qual foi devidamente explorada. Em termos de complexidade de treliça, a supertreliça mostrou ser consideravelmente menos complexa do que as treliças separadas. Tal vantagem se acentua com o aumento do comprimento da IES e da eficiência espectral. No que diz respeito à taxa de convergência, a supertreliça é mais rápida do que as treliças separadas, além de requerer um número menor de símbolos de treinamento. Por outro lado, para as treliças separa-

\footnotetext{
${ }^{3}$ Note que, uma vez que a detecção e a decodificação são muito mais complexas do que a estimação do canal e da variância, não se considerou essas últimas nos cálculos do esforço computacional.
}

das, devido ao fato de que nesse caso pode-se utilizar um entrelaçador de canal, o nível de diversidade que pode ser atingido é maior, sendo que essa diferença aumenta com o comprimento da IES. Entretanto, a diferença em diversidade nem sempre se traduz em uma grande diferença em termos de BER e, assim, o ganho em $\mathrm{dB}$ pode não compensar o tremendo acréscimo em complexidade computacional requerido pelas treliças separadas.

\section{AGRADECIMENTOS}

Este trabalho foi financiado pela CAPES (BEX2506/025) e pelo CNPQ (141577/2001-0, 472448/2003-0). O autor gostaria de agradecer a colaboração e o incentivo de André Luís Dalcastagnê, Bartolomeu F. Uchôa-Filho, Javier GarciaFrias e Mário de Noronha Neto.

\section{REFERÊNCIAS}

[1] E. Telatar, "Capacity of multi-antenna Gaussian channels," European Transactions on Telecommunications, pp. 585-595, Nov. 1999.

[2] G. J. Foschini and M. J. Gans, "On limits of wireless communications in a fading environment when using multiple antennas," Wireless Pers. Commun., vol. 6, pp. 311-335, 1998.

[3] V. Tarokh, N. Seshadri, and A. R. Calderbank, "Space-time codes for high data rate wireless communications: performance criterion and code construction," IEEE Trans. Inform. Theory, vol. 44, no. 2, pp. 744-765, Mar. 1998.

[4] V. Tarokh, A. F. Naguib, N. Seshadri, and A. R. Calderbank, "Space-time codes for high data rate wireless communications: performance criteria in the presence of channel estimation errors, mobility, and multiple paths," IEEE Trans. Commun., vol. 47, pp. 199-207, Feb. 1999.

[5] A. R. Hammons Jr. and H. El Gamal, "On the theory of spacetime codes for PSK modulation," IEEE Trans. Inform. Theory, vol. 46, no. 2, pp. 524-542, Mar. 2000.

[6] H. El Gamal and A. R. Hammons Jr., "On the design and performance of algebraic space-time codes for BPSK and QPSK modulation," IEEE Trans. Commun., vol. 50, no. 6, pp. 907 913, June 2002.

[7] M. Noronha-Neto, R. D. Souza, and B. F. Uchôa-Filho, "Space-time convolutional codes over GF(p) for the quasistatic flat Rayleigh fading channel," Revista da Sociedade Brasileira de Telecomunicações, vol. 18, no. 1, p.61-68, Jul. 2003.

[8] T. S. Rappaport, Wireless Communications: Principles and Practice, Prentice-Hall, 1996.

[9] E. Biglieri, J. Proakis, and S. Shamai, "Fading channels: information-theoretic and communications aspects," IEEE Trans. Inform. Theory, vol. 44, no. 6, pp. 2619-2692, Oct. 1998.

[10] G. Bauch and A. F. Naguib, "MAP equalization of spacetime coded signals over frequency selective channels," in Proc. IEEE WCNC'99, New Orleans, USA, Sep. 1999.

[11] A. F. Naguib and N. Seshadri, "MLSE and equalization of space-time coded signals," in Proc. IEEE VTC'00, Tokyo, Japan, May 2000.

[12] G. Bauch and N. Al-Dhahir, "Reduced-complexity space-time turbo-equalization for frequency-selective MIMO channels," IEEE Trans. Wireless Commun., vol. 1, no. 4, pp. 819-828, Oct. 2002. 
[13] N. Al-Dhahir, "Overview and comparison of equalization schemes for space-time-coded signals with applications to EDGE," IEEE Trans. Signal Proc., vol. 50, no. 10, pp. 2477 2488, Oct. 2002.

[14] A. P. Dempster, N. M. Laird, and D. B. Rubin, "Maximum likelihood from incomplete data via the EM algorithm," Journal of the Royal Statistical Society, vol. B39, p. 1-38, 1977.

[15] T. K. Moon, "The expectation-maximization algorithm," IEEE Signal Proc. Mag., vol. 13. no. 6, pp. 47-60, Nov. 1996.

[16] C. N. Georghiades and J. C. Han, "Sequence estimation in the presence of random parameters via the EM algorithm", IEEE Trans. Commun., vol. 45, no. 3, pp. 300-308, Mar. 1997.

[17] C. Cozzo and B. L. Hughes, "Joint channel estimation and data symbol detection in space-time communications," in Proc. IEEE ICC'00, New Orleans, USA, June 2000.

[18] Y. Li, C. N. Georghiades, and G. Huang, "Iterative maximumlikelihood sequence estimation for space-time coded systems," IEEE Trans. Commun., vol. 49, no. 6, June 2001.

[19] R. Matsuo, T. Ohtsuki, and I. Sasase, "Simple EM based channel estimation and data detection using estimation in the preceding frame in space-time coded signals," in Proc. IEEE ISIT'0I, Washington D.C., USA, June 2001.

[20] Z. Baranski, A. M. Haimovich, and J. Garcia-Frias, "Iterative channel estimation and sequence detection for space-time coded data," in Proc. 36th Annual Conference on Information Sciences and Systems - CISS'O2, Princeton, USA, Mar. 2002.

[21] Z. Baranski, A. M. Haimovich, and J. Garcia-Frias, "EMBased iterative receiver for space-time coded modulation with noise variance estimation," in Proc. IEEE Globecom 2002, Taipei. Taiwan, Nov. 2002.

[22] H. A. Cirpan and M. K. Tsatsanis, "Stochastic maximum likelihood methods for semi-blind channel estimation," IEEE Signal Proc. Letters, vol. 5, no. 1, pp. 21-24, Jan. 1998.
[23] E. de Carvalho and D. T. M. Slock, "Blind and semi-blind FIR multichannel estimation: (global) identifiability conditions," IEEE Trans. Signal Proc., vol. 52, no. 4, pp. 1053-1064, Apr. 2004

[24] Y. Liu, M. P. Fitz, and O. Y. Takeshita, "Space-time performance criteria and design for frequency selective fading channels," in Proc. IEEE ICC'01, Helsinki, Finlandia, May 2001.

[25] R. J. McEliece and W. Lin, "The trellis complexity of convolutional codes," IEEE Trans. Inform. Theory, vol. 42, no. 6, pp. 1855-1864, Nov. 1996.

[26] L. R. Bahl, J. Cocke, F. Jelinek, and J. Raviv, "Optimal decoding of linear codes for minimizing symbol error rate," IEEE Trans. Inform. Theory, vol. IT-20, pp. 284-287, Mar. 1974

[27] D. Cui, A. Haimovich, and H. Chen, "Parallel concatenated turbo multiple antenna coded modulation: principles and performance," Wiley Journal on Wireless Communications and Mobile Computing. Special Issue: Adaptive Antennas and MIMO Systems, vol. 2, pp. 735-751, Nov. 2002.

[28] A. J. Viterbi, "Error bounds for convolutional codes and an asymptotically optimum decoding algorithm," IEEE Trans. Inform. Theory, IT-13. pp. 260-269, Apr. 1967.

Richard Demo Souza nasceu em Florianópolis - SC, Brasil, em 1978. Obteve os títulos de Bacharel e Doutor em Engenharia Elétrica pela Universidade Federal de Santa Catarina em 1999 e 2003, respectivamente. Durante o ano letivo de 2003 foi Pesquisador Visitante do Departamento de Engenharia Elétrica e da Computação da University of Delaware, Newark-DE, EUA. Atualmente é Professor Adjunto do Departamento Acadêmico de Eletrônica e Colaborador do Programa de Pós-Graduação em Engenharia Elétrica e Informática Industrial, ambos do Centro Federal de Educação Tecnológica do Paraná (CEFET-PR), Unidade Curitiba. Suas áreas de interesse são teoria da codificação, comunicações sem fio e processamento digital de sinais. 